\title{
Anthrenus (s. str.) corona (Coleoptera, Dermestidae, Anthrenini): a new species in the $A$. pimpinellae Fabricius, 1775 complex from Turkey
}

\author{
GRAHAM J. HOLLOWAY \\ Centre for Wildlife Assessment and Conservation, School of Biological Sciences, Harborne Building, The University of Reading, \\ Whiteknights, Reading RG6 2AS, UK \\ झ"g.j.holloway@reading.ac.uk; @ https://orcid.org/0000-0003-0495-0313
}

\begin{abstract}
A new species from Turkey, Anthrenus (s. str.) corona, belonging to the Anthrenus pimpinellae complex is presented. The species is described from a single specimen discovered in the collection held by the Natural History Museum, London. The species was uncovered during the dissection of many specimens for the purpose of curation. The species is compared in detail to $A$. goliath, the most likely confusion species. An obvious external feature of the specimen is its large size, putting it apart from nearly all other species within the complex. The parameres and median lobe are slim, differing in many ways from $A$. goliath.
\end{abstract}

Key words: goliath, complex, dissection, genitalia, aedeagus, taxonomy

\section{Introduction}

The family Dermestidae Latreille 1804 contains over 1,700 described species worldwide (Háva 2020). One of the larger genera within the family is Anthrenus Geoffroy 1762, with about 260 species. The genus is split into 10 subgenera (Háva 2020), but the taxonomy is not yet well established. Kadej (2018) using juvenile characters showed that only the subgenus Anthrenus is monophyletic, concluding that the remaining subgenera form a polyphyletic unit. Holloway et al. (2020a) carried out a limited genetic analysis of the relationship between a few Anthrenus species and found evidence supporting Kadej (2018). Both studies suggest that the taxonomy of the genus Anthrenus has not yet been resolved.

The monophyletic taxon, Anthrenus (Anthrenus), contains around 70 species, including the large Anthrenus pimpinellae Fabricius 1775 complex. It has been known for a long time that the complex contains many species of similar appearance and this has made identification difficult (Beal 1998). Complexity within the group has resulted in a lack of knowledge of the number of species and, for each species, a lack of understanding of the distribution (Beal 1998; Holloway et al. 2019; Holloway \& Bakaloudis 2019; Holloway et al. 2020a, b). Beal (1998), Kadej et al. (2007) and Kadej \& Háva (2011) emphasized the importance of dissection for genital inspection to establish identification, arguing that it was required to circumnavigate the problem of colour pattern variation across the group. In taking this approach, Kadej et al. (2007) and Kadej \& Háva (2011) described six new species within the A. pimpinellae complex bringing the total number of species within the complex to 20. Holloway $(2019,2020)$ followed the advice provided by Beal (1998), and Kadej and colleagues that dissection is important and, in doing so, discovered two more species within the complex bringing the number of species known within the A. pimpinellae complex to 22 .

The work of Holloway $(2019,2020)$ and Holloway et al. (2020a) has indicated that perhaps there remain more species to be discovered in the A. pimpinellae complex and that this, most likely, can only be achieved via dissection. The requirement to dissect species belonging to the complex is also a problem for museum curation. During curation there is a need to sort specimens accurately according to species. Work is currently being carried out to dissect all specimens in the A. pimpinellae complex held by the Natural History Museum (NHM), London. This effort has demonstrated considerable confusion among species and resulted in the discovery of two new species, $A$. chikatunovi (Holloway 2020), and A. corona described here. 


\section{Materials and methods}

The nomenclature and zoogeography follow Háva $(2015,2020)$, and the conventional nomenclature, including of the taxa under study, is used. All specimens belonging to the Palaearctic A. pimpinellae complex were borrowed from the NHM (over 100 specimens). Each specimen was removed from its staging pin and dropped into $2 \%$ acetic acid for at least 3 days to make the insects fall away from the card on which they were set or to be removed from the pins piercing their bodies (as in the current case). The abdomen was detached from the thorax and the soft tergites peeled away from the harder ventrites to reveal the genitalia. The genitalia were placed into a drop of $70 \%$ ethanol to facilitate the removal of dried abdominal material from the genitalia under a stereo microscope using fine entomological pins. Sternite IX was removed from the aedeagus. The habitus, ventrites, tergites, aedeagus and sternite IX were arranged and fixed to new mounting card. The antennae were hooked out of the antennal cavities to facilitate inspection. Dissection was carried out under a Brunel BMSL zoom stereo LED microscope. Images were taken using a Canon EOS 1300D and fed through Helicon Focus 6-Pro focus stacking software. For the specimen described here, habitus and ventrite images were captured at x15 (BMSL), images of antennae were captured at x63 (BMSL), and images of the genitalia were captured at x100 using a Brunel monocular SP28 microscope. Morphometrics were taken using DsCap.Ink software.

The following morphometrics were taken:

Body length (BL)

Body width (BW)

Paramere length (PL)

Antennal club length (AL)

Antennal club width (AW) linear distance from the anterior margin of the pronotum to the tip of the elytra linear transverse distance across the widest point to the outer margins of the elytra (values were obtained for each elytron separately and summed)

linear length of one paramere from the apical tip of paramere to the base where the two parameres curve in on each other and meet.

maximum length of antennal club

maximum width of antennal club

\section{Results}

Anthrenus corona sp. nov.

Specimen examined. New record (holotype) for Anthrenus (Anthrenus) corona sp. nov. Turkey, Keçiören, 16 May 1939, F.S. Bodenheimer leg., one $\widehat{\partial}$, NHM, London, UK.

Description. External characteristics. Large $(\mathrm{BL}=4.434 \mathrm{~mm})$ and broadly oval $(\mathrm{BW}=3.297 \mathrm{~mm})($ Fig. $1 \mathrm{~A})$, BW/ $\mathrm{BL}=0.744$. Head with one median ocellus on vertex. Cuticle reddish brown on elytra, dark brown on pronotum. Dorsal surface covered in flat, oval scales, which are approximately twice as long as broad. Scales either black, orange, or creamy-white. Creamy-white scales concentrated in sub-basal, trans-elytral band, broadest at the lateral margin, narrowing towards the elytral suture. The scutellum is triangular and black. One sub-apical creamy-white spot on each elytron and two more diffuse creamy-white patches on the hind angles of the pronotum. Orange scales more scattered as small patches across the pronotum, around the elytral apices, along the apical half of the elytral suture and scattered as loose patches across the disk of each elytron posterior to the white band. Eyes emarginated on inner edge and mostly glabrous apart from a few scattered micro setae in top half of eye. Abdominal ventrites covered in closely packed white scales (Fig. 1B). Anterior $1 / 3$ of ventrite I devoid of scales. Anterior halves of lateral margins of ventrites II-V carry spots of black scales and there is a spot of black scales at the apex of ventrite V. Ventrite I also carries spots of black scales towards each lateral margin, but these spots are small, sublateral and surrounded by white scales. The femora, tibiae, and tarsi unicolorous mid-brown. Femora carry scales on the outer surface, especially basally. Antennae with 11 antennomeres, antennomeres 1-8 reddish brown (Fig. 1C). Antennomeres 9-11 form an asymmetric club ( $\mathrm{AL}=0.247 \mathrm{~mm}$; $\mathrm{AW}=0.180 \mathrm{~mm}$; $\mathrm{AL} / \mathrm{AW}=1.372)$ that is marginally darker than antennomeres $1-8$.

Internal characteristics. $\mathrm{PL}=0.572 \mathrm{~mm} . \mathrm{PL} / \mathrm{BL}=0.129$, aedeagus (Fig. $2 \mathrm{~A}$ ) short relative to $\mathrm{BL}$ compared with equivalent measures in some other species (Holloway \& Bakaloudis 2020; Holloway et al. 2020a). Parameres carry hairs on the apical third. The spikey hairs on the outer surface of each paramere are noticeable and unusual. Also, 
some sparsely distributed hairs on inner surface of each paramere starting marginally further away from the apical tip than hairs on outer surface. Inner surfaces of each paramere at the apical tip carry several short, spikey hairs emerging at right angles from each paramere pointing inwards. Parameres very narrow, evenly curved from base to apex. Parameres expand slightly at apex forming blunt, rounded, and white tips that tilt in towards each other. The white patches extend further down the inner margins of the parameres than the outer margins. Median lobe has a wide base and narrows rapidly towards the apex until about halfway along its length from which point it barely narrows any further, forming an almost parallel-sided finger to the apex. Apical tip of median lobe evenly rounded, without expansion, falling short of tips of parameres. Apical (posterior) end of sternite IX (Fig. 2B) spatulate. Margins of expanded apex of sternite IX carry sharp hairs, including around the evenly rounded tip. From the apex towards the anterior end, posterior stem narrows forming a neck before expanding rapidly towards two slim horns pointing into abdomen. Fig. 2C illustrates structure of the evident, but narrow, sclerotinized margins, just posterior to the neck that expand evenly to terminate at the base of each horn. Horns similarly sclerotinized with contrast between colour at base of each horn and the broad ends of the sclerotinized margins described above. Between the horns, the membrane is translucent. From apex to base, sternite IX $=0.626 \mathrm{~mm}$.
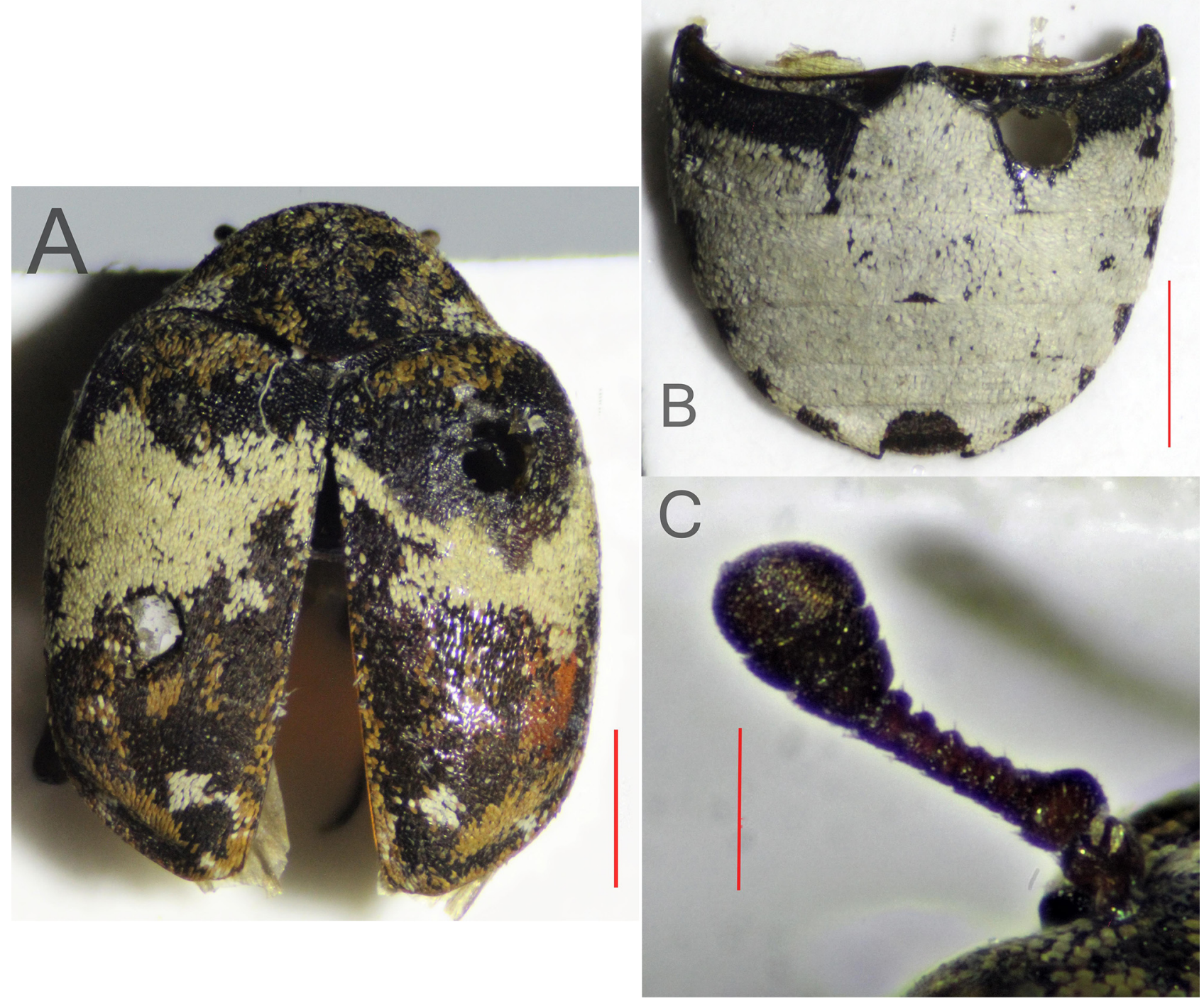

FIGURE 1. External features of $ð$ Anthrenus corona: A, habitus dorsal aspect (scale bar: $1 \mathrm{~mm})$; B, ventrites (scale bar: $1 \mathrm{~mm}$ ); C, antennal club (scale bar: $0.2 \mathrm{~mm}$ ).

Differential diagnosis. External characteristics. The most striking feature of the specimen shown in Fig. 1A is its size. The only other species in the complex that approaches this size and has a colour pattern resembling $A$. corona is $A$. goliath Mulsant \& Rey 1868 (Fig. $3 \mathrm{~A}$ ). NHM holds just one $A$. goliath: $\mathrm{BL}=3.962 \mathrm{~mm}, \mathrm{BW}=3.171$ $\mathrm{mm}, \mathrm{BW} / \mathrm{BL}=0.700$. The NHM $A$. goliath specimen has a narrower habitus profile than $A$. corona. Fig. $3 \mathrm{~B}$ shows 
an image of an antenna from A. goliath. Anthrenus goliath has a slim, asymmetric antennal club ( $\mathrm{AL}=0.250 \mathrm{~mm}$, $\mathrm{AW}=0.165 \mathrm{~mm}, \mathrm{AL} / \mathrm{AW}=1.515$ ). Anthrenus corona also has an asymmetric antennal club (Fig. $1 \mathrm{C}$ ) that is not as narrow as $A$. goliath.

Internal characteristics. Anthrenus corona has very narrow aedeagal parameres (Fig. 2A). The parameres of A. goliath (Fig. 3C) are considerably broader than A. corona. The setae on A. goliath parameres are short, sparse and cover the surface of the parameres, in contrast to the spikey setae along the paramere margins in $A$. corona. Anthrenus goliath $\mathrm{PL}=540 \mu \mathrm{m}, \mathrm{PL} / \mathrm{BL}=0.136$, so the aedeagus in $A$. goliath is longer relative to $\mathrm{BL}$ than $A$. corona. The median lobe of $A$. goliath is broader for much of its length than the median lobe of $A$. corona.
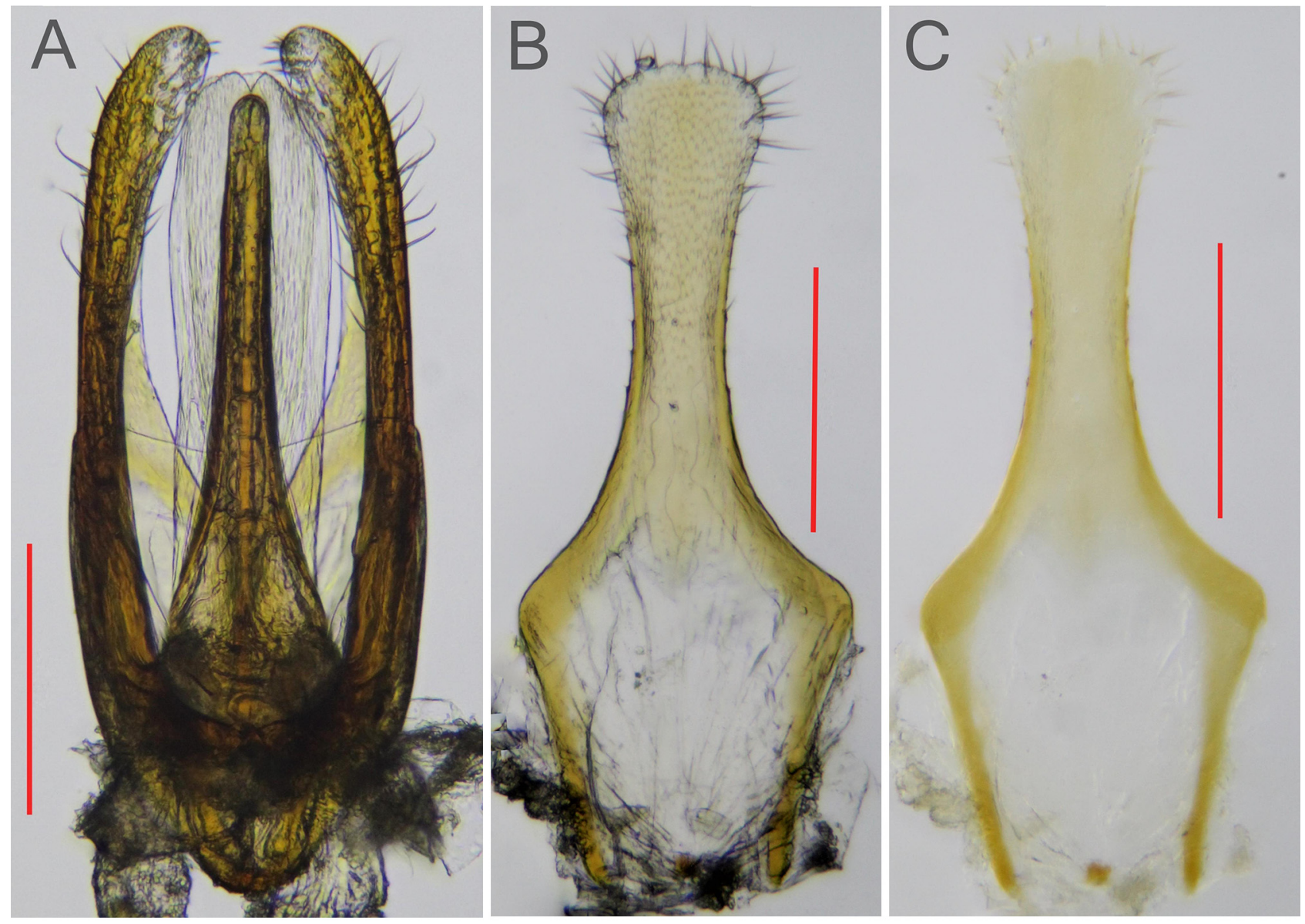

FIGURE. 2. Genitalia of $\lesssim$ Anthrenus corona: A, aedeagus dorsal aspect, low intensity transmitted light to highlight setae; B, sternite IX, low transmitted light intensity to highlight setae; C, sternite IX, high transmitted light intensity to highlight sclerotinized features. Scale bars: $0.2 \mathrm{~mm}$.

Discussion. The specimen of $A$. corona described here is large at $4.434 \mathrm{~mm}$. Kadej et al. (2007) examined 60 specimens of $A$. goliath and found body length to vary between $3.0 \mathrm{~mm}$ and $4.25 \mathrm{~mm}$. The only $A$. goliath held by the NHM measures $3.962 \mathrm{~mm}$. However, the $A$. corona specimen has a much rounder profile $(\mathrm{BW} / \mathrm{BL}=0.744)$ than $A$. goliath $(\mathrm{BW} / \mathrm{BL}=0.700)$. Holloway \& Bakaloudis (2020) and Armstrong et al. (submitted) found $\mathrm{BW} / \mathrm{BL}$ to be highly conserved, so it is likely that $A$. goliath is a consistently slimmer species than A. corona. According to Háva (2020), Anthrenus goliath also occurs in Turkey. It would be interesting to get more body measurements for A. corona to establish whether body size and shape could be an initial guide to identification. Genital structure remains the principal way of differentiating among species within the $A$. pimpinellae complex. Even when habitus characteristics are very similar, genital structure varies consistently among species (Kadej et al. 2007) but varies very little within species (Holloway \& Bakaloudis 2020; Holloway et al. 2020a).

The discovery of $A$. corona brings the number of known species within the Anthrenus pimpinellae complex to 23. One further species within the A. pimpinellae complex is claimed: A. almatyensis Háva 2018 (Háva 2018). Unfortunately, the quality of the images provided in Háva (2018) does not offer readers the opportunity to explore the calibre of the claim, in particular differentiation from the similar A. mesopotamicus Háva 2001 (Kadej et al. 2007). 
Etymology. Anthrenus corona is named after the COVID-19 pandemic that has been causing so much suffering globally at the time this species was discovered.

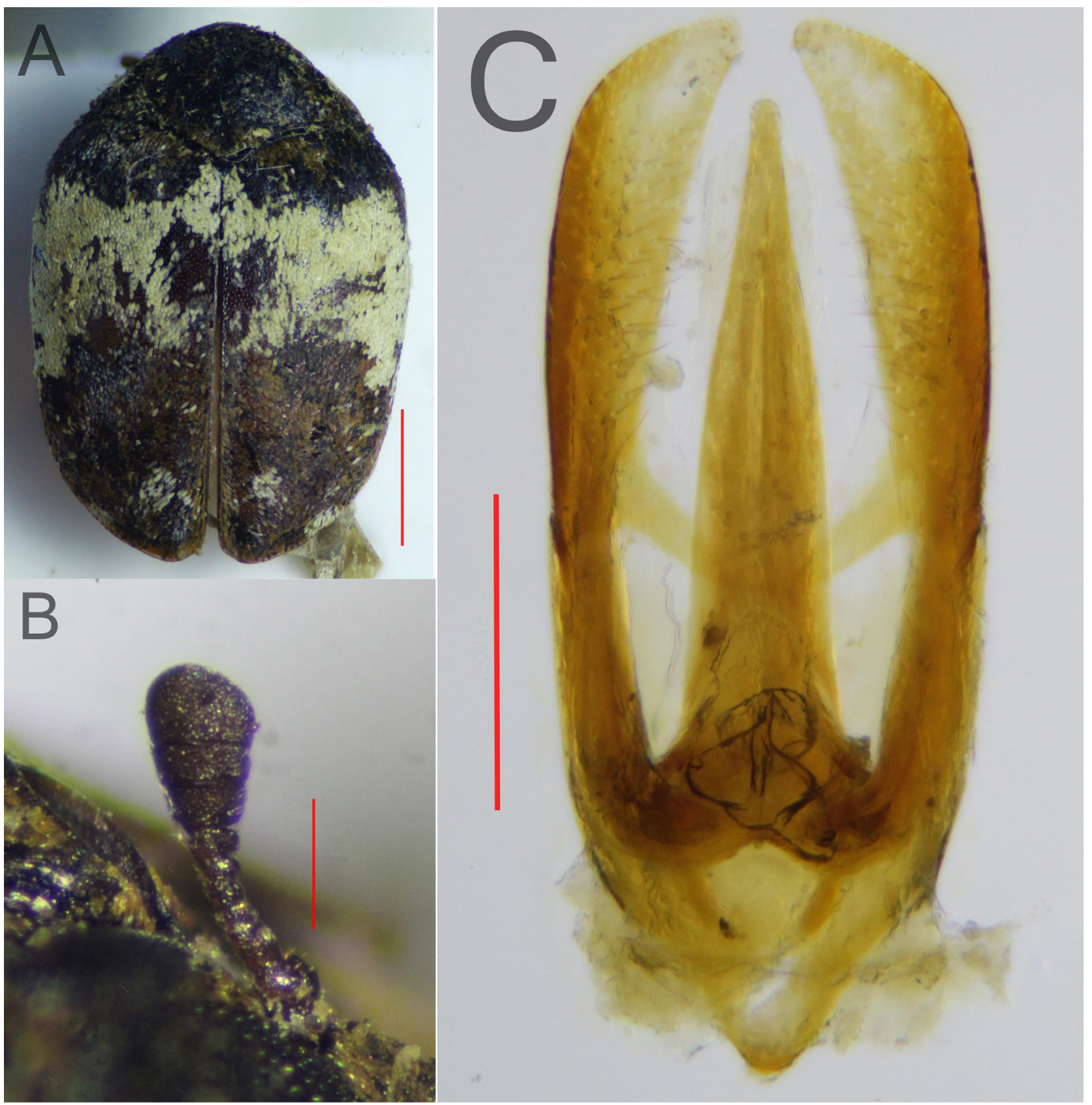

FIGURE 3. $\lesssim$ Anthrenus goliath: A, habitus dorsal aspect (scale bar: $1 \mathrm{~mm}$ ); B, antennal club (scale bar: $0.2 \mathrm{~mm}$ ); , aedeagus dorsal aspect (scale bar: $0.2 \mathrm{~mm}$ ).

\section{Acknowledgements}

I am very grateful to Max Barclay and the rest of the Coleoptera curatorial team of the Natural History Museum, London, for providing access to the collections in their care. I am also very grateful to two reviewers and the editor for their excellent suggestions on how to improve the manuscript. 


\section{References}

Armstrong, E., Bakaloudis, D.E. \& Holloway, G.J. (2021) A morphometric examination of Anthrenus flavipes flavipes Le Conte 1854 (Coleoptera: Dermestidae: Anthrenini). Fragmenta Entomologica. [submitted]

Beal Jr., R.S. (1998) Taxonomy and Biology of Nearctic Species of Anthrenus (Coleoptera: Dermestidae). Transactions of the American Entomological Society, 124 (3 \& 4), 271-332.

Háva, J. (2015) World Catalogue of Insects. Vol. 13. Dermestidae (Coleoptera). Brill, Leiden and Boston, xxvi +419 pp. https://doi.org/10.1163/9789004286610

Háva, J. (2018) Anthrenus (Anthrenus) almatyensis sp. nov. from Kazakhstan (Coleoptera: Dermestidae: Megatominae). Studies and Reports Taxonomical Series, 14 (2), 255-258.

Háva, J. (2020) Dermestidae (Insecta: Coleoptera). Available from: http://dermestidae.wz.cz/wp-content/uploads/2020/01/ Subfamily-Megatominae.pdf (accessed 25 October 2020)

Holloway, G.J. (2019) Anthrenus (s. str.) amandae (Coleoptera: Dermestidae): a new species from Mallorca, Spain. Zootaxa, 4543 (4), 595-599. https://doi.org/10.11646/zootaxa.4543.4.9

Holloway, G.J. (2020) Anthrenus (s. str.) chikatunovi (Coleoptera, Dermestidae, Anthrenini): a new cryptic species in the $A$. pimpinellae Fabricius 1775 complex from southern France. Israel Journal of Entomology, 50 (2), 69-75. http://doi.org/10.5281/zenodo.4088743

Holloway, G.J. \& Bakaloudis, D.E. (2019) New distributional record of Anthrenus dorsatus Mulsant \& Rey, 1968 (Coleoptera, Dermestidae), Thessaloniki, Greece. Check List, 15(6), 1077-1081. https://doi.org/10.15560/15.6.1077

Holloway, G.J. \&Bakaloudis, D.E. (2020) A Comparative Morphological Study of Anthrenus pimpinellae pimpinellae (Fabricius, 1775) and Anthrenus amandae Holloway, 2019 (Coleoptera: Dermestidae). Coleopterists Bulletin, 74 (2), 315-321. https://doi.org/10.1649/0010-065X-74.2.315

Holloway, G.J., Foster, C.W. \& Callaghan, A. (2019) New distributional record of Anthrenus dorsatus Mulsant \& Rey, 1868 (Coleoptera, Dermestidae) on the Island of Mallorca, Spain. Check List, 15 (1), 33-36. https://doi.org/10.15560/15.1.33

Holloway, G.J., Bakaloudis, D.E., Barclay, M.V.L., Cañada Luna, I., Foster, C.W., Kadej, M. \& Paxton, R.J. (2020a) Revision of taxonomic status of Anthrenus pimpinellae isabellinus (Coleoptera; Dermestidae). European Journal of Entomology, $117,481-489$. https://doi.org/10.14411/eje.2020.051

Holloway, G.J., Bakaloudis, D.E. \& Foster, C.W. (2020b) Anthrenus dorsatus new to the United States and a comparison with Anthrenus pimpinellae ssp. pimpinellae (Coleoptera: Dermestidae). Journal of the Kansas Entomological Society. [in press]

Kadej, M. (2018) Contribution to knowledge of the immature stages of Dermestidae with species emphasis on the larval morphology of the genus Anthrenus Geoffroy, 1762 (Megatominae, Anthrenini). Polish Entomological Monographs No 16. Polish Entomological Society, Poznań, 180 pp.

Kadej, M. \& Háva, J. (2011) Three new species of Anthrenus pimpinellae species group from Palaearctic Region (Coleoptera: Dermestidae: Megatominae: Anthrenini). Studies and Reports Taxonomical Series, 7 (1-2), 241-248.

Kadej, M., Háva, J. \& Kalík, V. (2007) Review of the Anthrenus pimpinellae species group from Palaearctic region (Coleoptera: Dermestidae: Anthrenini). Genus, 18 (4), 721-750. 